\title{
Field Emission Scanning Electron Microscopy (FESEM) characterisation of the porous silica nanoparticulate structure of marine diatoms
}

\author{
P. Gnanamoorthy • V. Karthikeyan • \\ V. Ashok Prabu
}

Published online: 17 December 2013

(c) The Author(s) 2013. This article is published with open access at Springerlink.com

\begin{abstract}
Diatoms are unicellular algae that synthesize cell wall with silica that has highly ornate features on the nano to microscale. The porous silica nanoparticulate structure of three marine centric and one pennate diatoms namely, Coscinodiscus concinnus, Coscinodiscus sp., Odontella mobiliensis and Navicula directa were investigated by Field Emission Scanning Electron Microscopy (FESEM). Important morphological features like porous pattern, topography, pore size and shape were studied. The external layer (cribellum) of $C$. concinnus was found to be consisting of a characteristic pentagonal array of pores which were star in shape and irregular in size, with a diameter of $224.7 \mathrm{~nm}$ and a pore-to-pore distance of $160.6 \mathrm{~nm}$. The second diatom species investigated, Coscinodiscus sp. showed frustule with radially-oriented pattern of alternating grid-like arrangements of pores with honeycomb topography with pore diameter of 132.1 and distance between arrays were $61.01 \mathrm{~nm}$. The $O$. mobiliensis images showed well organisation of holes (foramen) showed hexagonal organisation and all the pores are circular with same size and pores of $328.6 \mathrm{~nm}$ diameter with pore to pore distance was $252.8 \mathrm{~nm}$. The girdle view of $N$. directa was about $5 \mu \mathrm{m}$ in diameter with values showing striae are parallel in whole and porous were observed in $N$. directa in the range of $278.3 \mathrm{~nm}$, the gaps between regularly arranged pores were $145.6 \mathrm{~nm}$ was clearly observed. The internal and external structures of all the diatom frustules were different in pore arrangements. The present study showed that high-resolution FESEM results revealed the silica nanostructure with nanoporous material exhibited
\end{abstract}

P. Gnanamoorthy $(\varangle) \cdot$ V. Karthikeyan · V. A. Prabu

Centre of Advanced Study in Marine Biology, Faculty of Marine

Sciences, Annamalai University, Parangipettai 608 502, India

e-mail: pg.moorthy87@gmail.com interesting application in antireflection, drug delivery and heavy metal adsorbing studies, which should be investigated further research will be a subject of future proposals by a flat form of present investigation.

Keywords Diatoms - Field Emission Scanning Electron Microscopy $\cdot$ Pores $\cdot$ Silica frustules $\cdot$ Nanoparticulate

\section{Introduction}

Biological nanomaterials have been mainly used in manufacturing products due to their movable synthetic ratio, green and renewable situation, complex arrangements, and natural enhanced functions [1,2]. Diatoms are unicellular photosynthetic algae with exoskeletons, called as frustules which consist of amorphous hydrated silica valves, self-assembled with highly organised pore arrangements [3]. The distinctive feature of diatoms is the biomineralised cell wall (frustule) comprising of two halves, the thecae, which can be separated into a valve and one or more girdle bands. The thecae overlapping like a petri dish during the cell division. The valves and girdles are arranged with compartments (areolae) and pores (cribra) in the form of periodic patterns [4].

Diatom frustules possess several excellent functions and potential for micro- and nanoscale manufacturing [5]. Since two decades, an incredible extent of strength has been made in the expansion of science and technology in nanoscience administration due to the innovative optical and electrical assets of submicron and nanostructured materials, which can be functional for fabrication of optoelectronic and photonic devices [6].

The fabrication of nanomaterials is a virtuous model of a rapidly developing field of nanotechnology, so the growth of investigational protocols for the synthesis of 
nanoparticles over a range of chemical compositions, sizes, and high monodispersity is one of the challenging problems in current nanotechnology [7]. Nowadays, biomaterials provide a new source of inspiration for design and fabrication of advanced nano-structured materials. There are various instances of organisms capable of
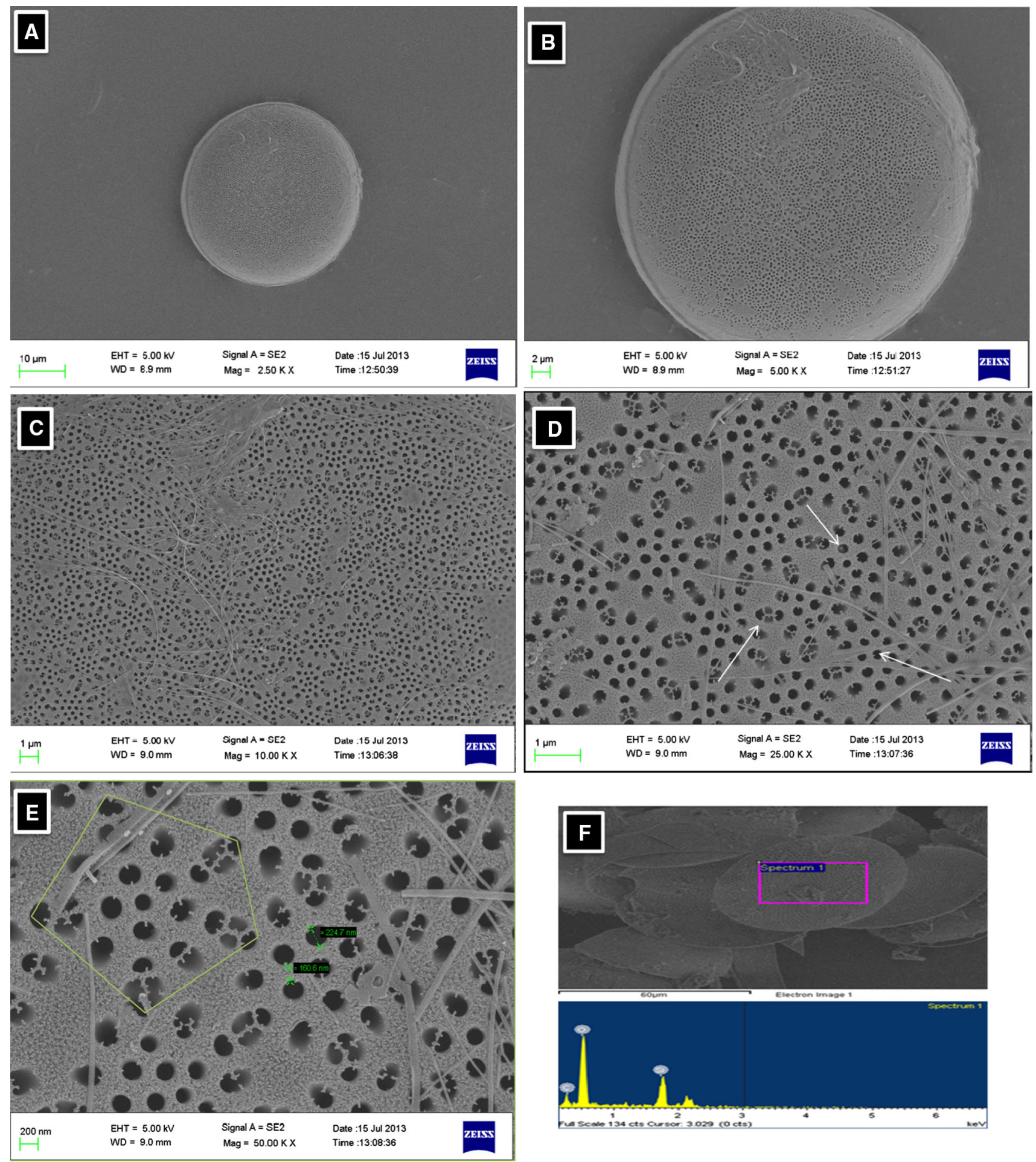

Fig. 1 Whole structure of $C$. concinnus (a). FESEM image $(2 \mu \mathrm{m})$ of the surface showing the porous topography (b). c Well-arranged FESEM image of foramen surface. d Enlarged FESEM image of a foramen shows details of pore organisation $(1 \mu \mathrm{m})$. e High resolution
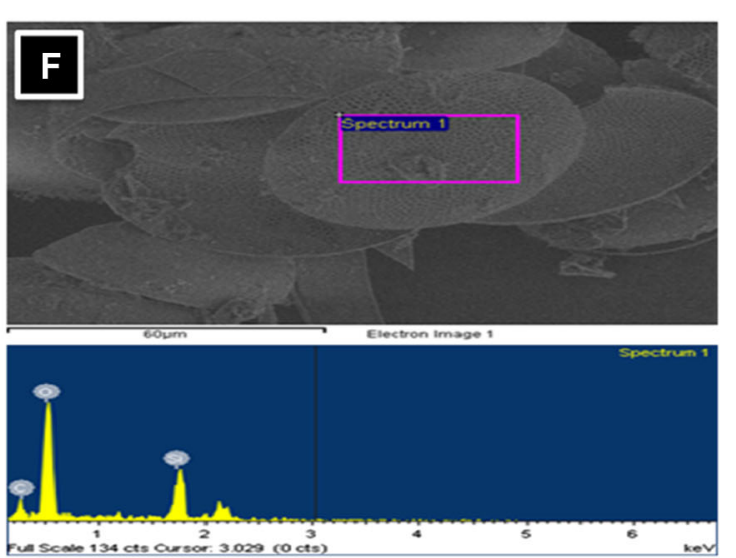

FESEM image of one typical pentagonal pattern is marked on pore array and star shaped hyaline area of surface of diatom with nanoporous diameter and inter pore distance details. f Corresponding EDS graph shows the silica element presence 
synthesizing inorganic-based structures into complicated architectures with ordered features from the microscale to the nanoscale, and an interesting process is the exceptional variety of patterned silica structures generated by diatoms [8].

The 3D quasi-regular constructions of diatom valves have been proposed are called diatom nanotechnology for the applications in the fields of optics, biophotonics, biosensing, filtration, microfluidics, drug delivery and heavy metal adsorbent [9-13]. Diatoms can routinely be grown to more than million cells per ml of culture medium, which offers the possibility of cheap production of nanostructured silica.

Varied analytical apparatuses have been used for the characterisation of diatom frustules counting from scanning electron microscopy (SEM), transmission electron microscopy (TEM), confocal microscopy, atomic force microscopy (AFM), Fourier transform infrared spectroscopy (FTIR), X-ray scattering (SAXS), and X-ray photoelectron spectroscopy (XPS) [14-19]. Conventionally, SEM and TEM are most frequently used in the study of diatom morphology and taxonomy. However, advanced 6th generation Field Emission Scanning Electron Microscopy (FESEM) based studies suggested significant advantages like: focusing with higher resolution, ability to measure structural and micromechanical properties and the potential of imaging in well accuracy mannar [20-22].

Therefore, in the present investigation, FESEM was used to examine the frustule topography of four marine diatom species. These biomineralised diatoms have interesting silica assemblies and this is the first work on FESEM study of these Coscinodiscus concinnus, Coscinodiscus sp., Odontella mobiliensis and Navicula directa species. The main attention of this study was to acquire detailed information about porous biosilica nanostructures and higher resolution images of external and internal frustule films. The better understanding of diatom nanostructure will be create the three dimensional nanoporous in a hierarchical way with multifunctional properties, which provide biomimetic model of silica structures at the microscale to nanoscale in diatoms [23-25]. It will further help in explaining the unknown functions of nano-porous biosilica for potential technological applications.

\section{Materials and methods}

\subsection{Diatom collection}

Phytoplankton (Diatom) samples were collected from Vellar estuary, Tamil Nadu, India. The phytoplankton net is made up of bolting silk cloth no 30, mesh size $48 \mu \mathrm{m}$ and mouth diameter of $0.35 \mathrm{~m}$. During sampling the net was submerged in the water and towed horizontally from a mechanized boat with an outboard engine at a speed of 0102 knots for half an hour. Collected samples was adopted for numerical analysis using the light microscope and identified by the standard keys of Prescott and Steidinger and Williams [26, 27].

\subsection{Laboratory culture of diatom}

Three marine centric diatoms namely $C$. concinnus, Coscinodiscus sp., O. mobiliensis and one pennate diatom ( $N$. directa) were cultured in $\mathrm{f} / 2$ Guillard's medium by following the standard methods of Anderson et al. [28, 29]. Pure auxenic cultures of four diatom species were maintained under controlled conditions of temperature $25 \pm 0.5{ }^{\circ} \mathrm{C} / 20 \pm 0.5{ }^{\circ} \mathrm{C}$ day/night cycles; photoperiods $12 \mathrm{~h}$ light (fluorescent lamps) and $12 \mathrm{~h}$ dark period in the algal culture laboratory of Centre of Advanced Study in Marine Biology, Annamalai University of India.

\subsection{Cleaning of diatom frustules}

In order to examine the diatom frustules under FESEM, a cleaning procedure Butcher et al. [30] was followed to remove extracellular organic layers from the frustules. Auxenic cultures of diatoms in conical flask were shaken for $4 \mathrm{~min}$ to detach all the cells and $15 \mathrm{ml}$ of each species was centrifuged at $6,000 \mathrm{rpm}$ for $10 \mathrm{~min}$ then the pellet was washed with deionized water for four times to eliminate any additional fixatives. The pellets were treated with $10 \% \mathrm{H}_{2} \mathrm{O}_{2}$ and kept in water bath for $15 \mathrm{~min}$ at $100{ }^{\circ} \mathrm{C}$ and $10 \%$ aqueous $\mathrm{HCl}$ was added and then centrifuged at $2,000 \mathrm{rpm}$ for $10 \mathrm{~min}$. The supernatant was pipetted out and the pellet was washed again with double distilled water for three times. Cleaned frustule valves were then stored in ethanol to avoid contamination.

\subsection{FESEM-characterisation of diatom frustules}

For FESEM studies, cleaned frustules of the diatoms were deposited on silicon coated with a thin gold layer and mounted on microscopy stubs with carbon sticky tape. The principal step of the characterisation was to trickle a few drops of the methanol suspended diatom samples on an aluminum sample holder for use in SEM. The methanol was evaporated off the sample holder, leaving many

Table 1 EDS table shows the element compositions of $C$. concinnus

\begin{tabular}{lcl}
\hline Element & Weight $(\%)$ & Atomic $(\%)$ \\
\hline Carbon & 9.60 & 14.58 \\
Oxygen & 54.36 & 62.00 \\
Silica & 36.04 & 23.42 \\
Total & 100.00 & \\
\hline
\end{tabular}



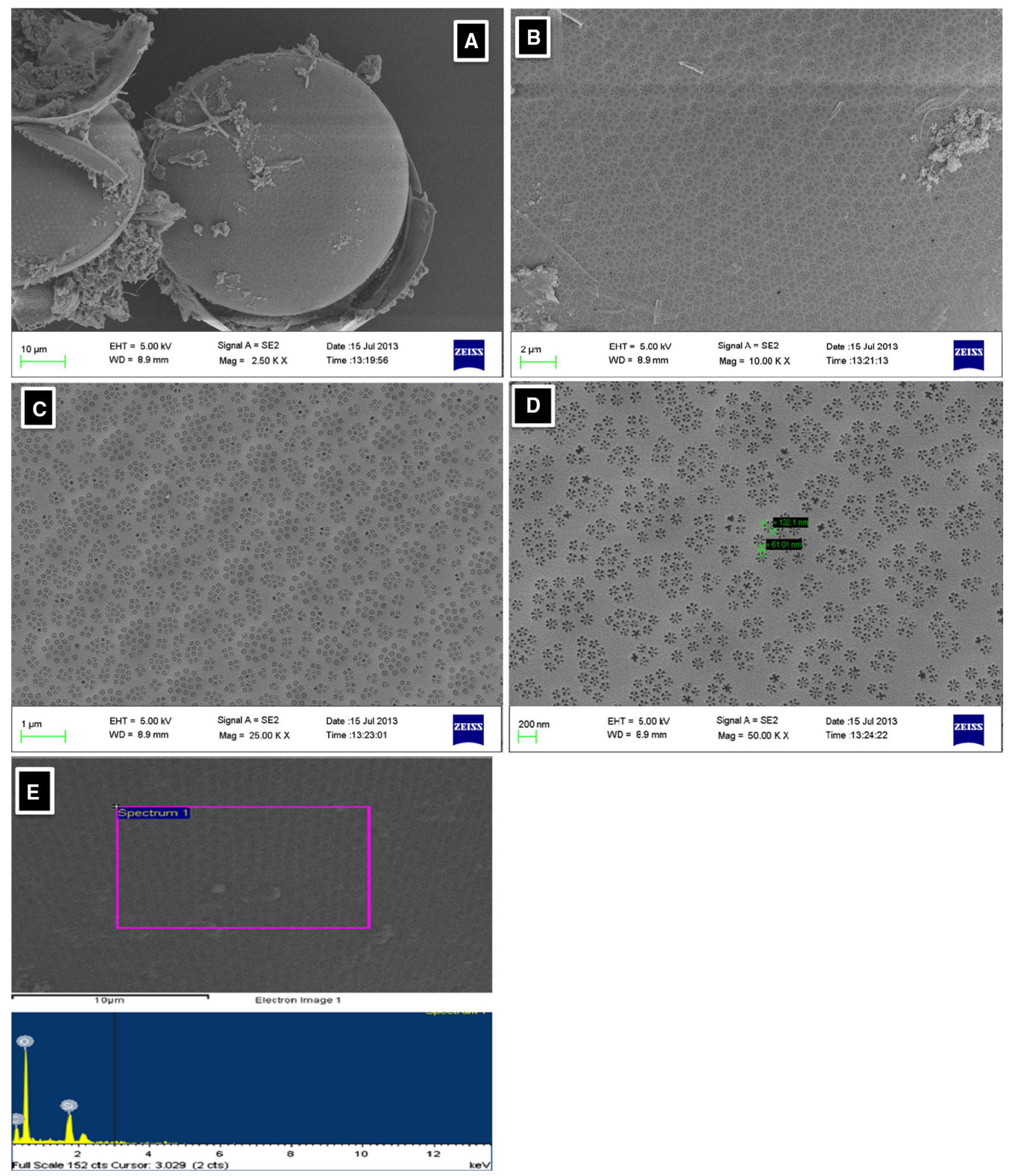

Fig. 2 Whole structure of Coscinodiscus sp. and large scale FESEM image of cribrum surface showing a regular honeycomb-like structures. Circular pattern is marked shown in (a). b FESEM image of cribrum surface, $\mathbf{c}$ FESEM image of cribrum in more detail; Circular rings pointed some irregularities domes arrangement. d High

resolution FESEM image of one typical dome pattern is marked the pore array of diatom with porous width and inter pore length details showing granular topography of accumulated silica nanoparticles. e EDS graph expressions the silica component existence 
frustules across the surface of the holder. The sample holder was then inserted into the SEM for characterisation and imaging. The images were acquired using a Carl Zeiss ultra 55 Field-Emission Scanning Electron Microscope operated at $5 \mathrm{kV}$ with X-ray spectroscopy (EDS). The pore size of the different pores was measured with the measuring software following the SEM. The SEM-imaging was conducted to make measurements of the diverse pore structures of the frustule as a large volume of data would be needed to be sure with the models are of excellence.

\section{Results and discussion}

\subsection{FESEM imaging of nanostructure Coscinodiscus concinnus}

The pure laboratory cultured $C$. concinnus species was investigated. Description about the nanostructure of $C$. concinnus is presented in Fig. 1 with representative FESEM images taken in electron 2 mode. This diatom was found to have a homogeneous size distribution with radius of $220 \pm 15 \mu \mathrm{m}$. A typical topographic SEM image, which represents the whole surface of C. concinnus was shown in Fig. 1a, b. This surface features a mounded topography with about $2 \mu \mathrm{m}$ wide porous domes organized on the surface in pentagonal packing. The valve face is slightly concave and exhibits a radiating pore pattern consisting of irregular pores called foramen. A comparative FESEM image (Fig. 1c) shows similar and smaller pores organization, named foramen pores. A more detailed FESEM image of this foramen arrangement structure is presented in Fig. 1d.

The basic feature of this silica structure was an array of 10-11 small pores consisting of about one array per dome arranged in a roughly pentagonal lattice with star-shape pore arrangement (Fig. 1e). The average diameter $195 \pm 15 \mathrm{~nm}$ arrays were observed. The distance between arrays was $160.6 \mathrm{~nm}$. Within each array, 5-6 pores were generally arranged around a central pore. Both irregular size and circular shaped pores were observed, with the diameters of $224.7 \mathrm{~nm}$ and a pore-to-pore distance of $160.6 \mathrm{~nm}$ (Fig. 1e). Elemental composition of the silica frustules was confirmed by EDS (Table 1; Fig. 1f). Although the hillock topography appears both in the foramen and cribrum, the cribrum domes have much more regular shapes and packing. Interestingly, in previous SEM studies these dome structures in the cribrum were observed or interpreted as depressions [31-33].

The diatom frustules exhibited the good mechanical strength, which is in accordance with the recent findings results [35]. The macroscopic mechanical strength of the frustule is apparently the result of both its pore construction and the characteristic mechanical properties of the nanostructured biosilica were reported as recent know [34].

\subsection{Characteristics of the Coscinodiscus sp. valve}

The valve of Coscinodiscus sp. was circular and on an average 7-8 $\mu \mathrm{m}$ in diameter. A series of FESEM images of the outer layer of the frustule of Coscinodiscus sp. is presented in Fig. 2. The distal valve surface consists of a radially-oriented pattern of alternating grid-like arrangements of pores (Fig. 2a, b). The large-scale image of the cribellum surface shows honeycomb topography with domes arranged almost in perfect hexagonal shape (Fig. 2c). The natural structure of this silica nanoparticulate is an array of 6-7 small pores with about 15 arrays per dome arranged in a roughly hexagonal shape and some of them are irregular shape frame. These arrays are $132.1 \mathrm{~nm}$ in diameter. The based on rational observation of whole diatom structure of distance between arrays was $61.01 \mathrm{~nm}$. Within each array, 4-7 pores are generally arranged around a central pore (Fig. 2d). Figure 2e and Table 2 shows the EDS graph of silica component existence was noted. This cribellum layer characterizes the external filter dish layer in contact with the exterior environment. Therefore its structural features like general topography, pore size, pore organisation and density are very important for nutrient uptake, sorting nutrients, and defence against bacterial and viral attack. The observed pore size suggests that this layer can successfully act as mechanical barrier or filter that allows passage for particles smaller than $45 \mathrm{~nm}$ which are unlikely to be of viral nature and more likely to be salubrious [3]. The function of the wave-like topography of the domes and the hexagonal organisation scaled from top (domes) to bottom (arrays and pores) remains to be elucidated [3].

Some of the observed morphological characteristics were already known from previous SEM studies, but has not been reported using FESEM [35-37]. FESEM results revealed that all structures of diatom were formed from silica nanoparticulate (Fig. 2d), and these accumulate into larger particles which are systematized on a supplementary higher level to form mesoscale structure. Diatom silica nanoparticulate has been noticed previously in valve cross-

Table 2 EDS table shows the element compositions of Coscinodiscus sp.

\begin{tabular}{lcl}
\hline Element & Weight $(\%)$ & Atomic $(\%)$ \\
\hline Carbon & 13.65 & 19.92 \\
Oxygen & 55.64 & 60.92 \\
Silica & 30.71 & 19.16 \\
Total & 100.00 & \\
\hline
\end{tabular}



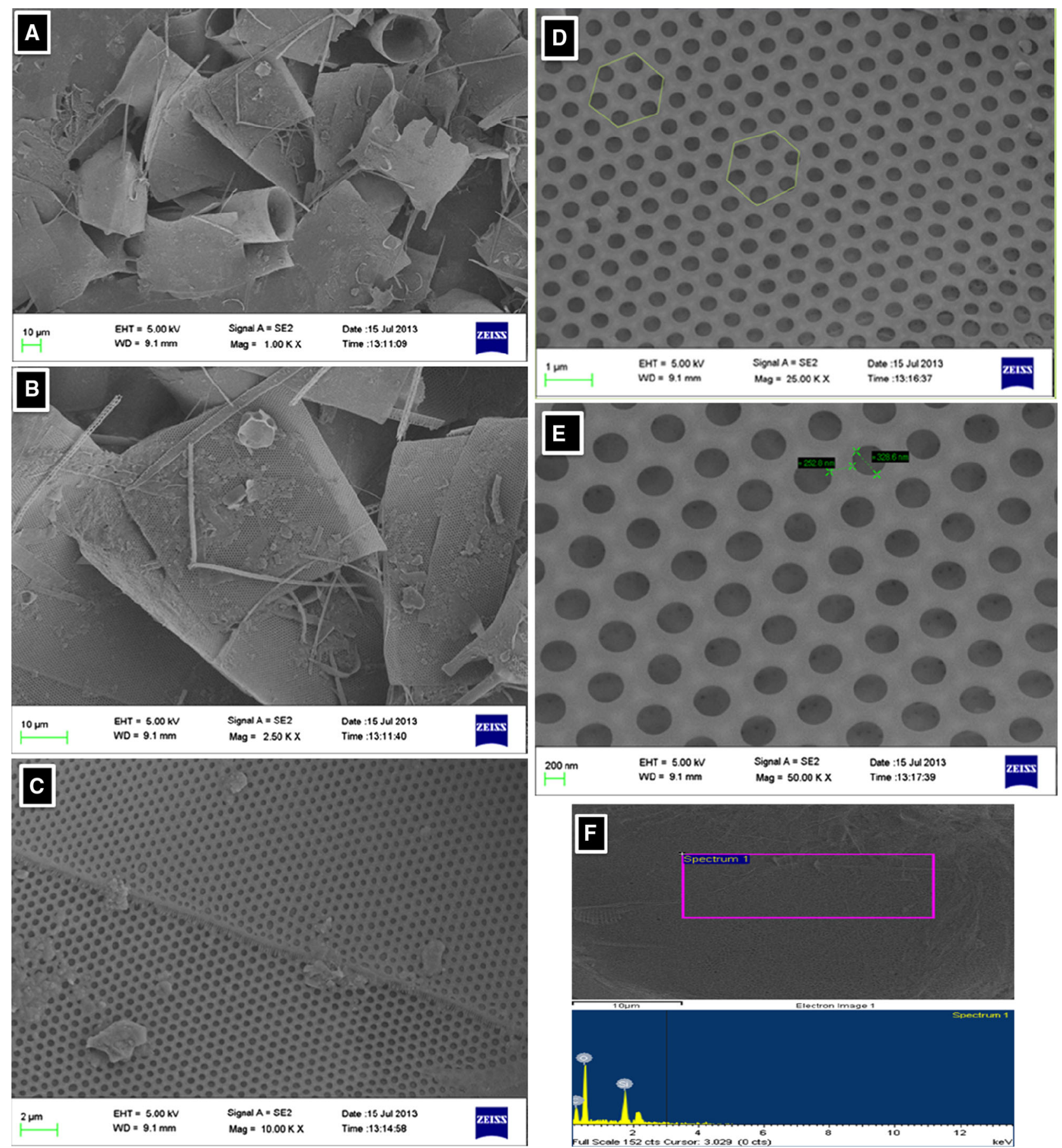

Fig. 3 Large Frustules of $O$. mobiliensis a. Large scale focusing of FESEM image shows of convex, with flat frustules (b). c Outer surface of $O$. mobiliensis image shows organisation of holes (foramen). d FESEM image of outer surface in more detail, showing hexagonal

sections and the surfaces [3, 36-39]. Particle formation and association is a thermodynamically-favored aspect of silica polymerization chemistry [40]. In diatoms, particle formation is catalytically promoted by the interaction between silaffins, long chain polyamines (LCPAs), and silacidins, though the silica particles do not naturally self-organize
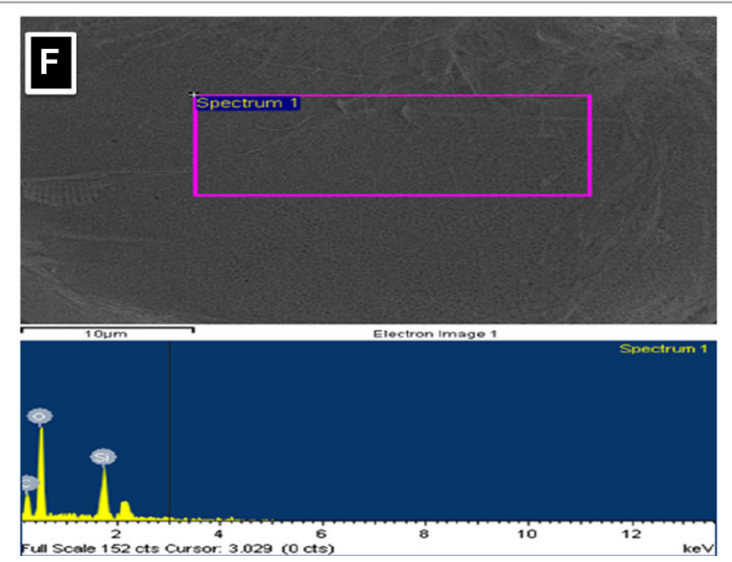

organisation. e FESEM images of ridge surface between two foramen openings revealing granular topography on the nanoscale. $f$ EDS graph of the centric marine diatom frustules (O. mobiliensis)

Table 3 EDS table shows the element compositions of $O$. mobiliensis

\begin{tabular}{lcl}
\hline Element & Weight $(\%)$ & Atomic $(\%)$ \\
\hline Carbon & 17.18 & 25.16 \\
Oxygen & 48.55 & 53.38 \\
Silica & 34.27 & 21.46 \\
Total & 100.00 & \\
\hline
\end{tabular}



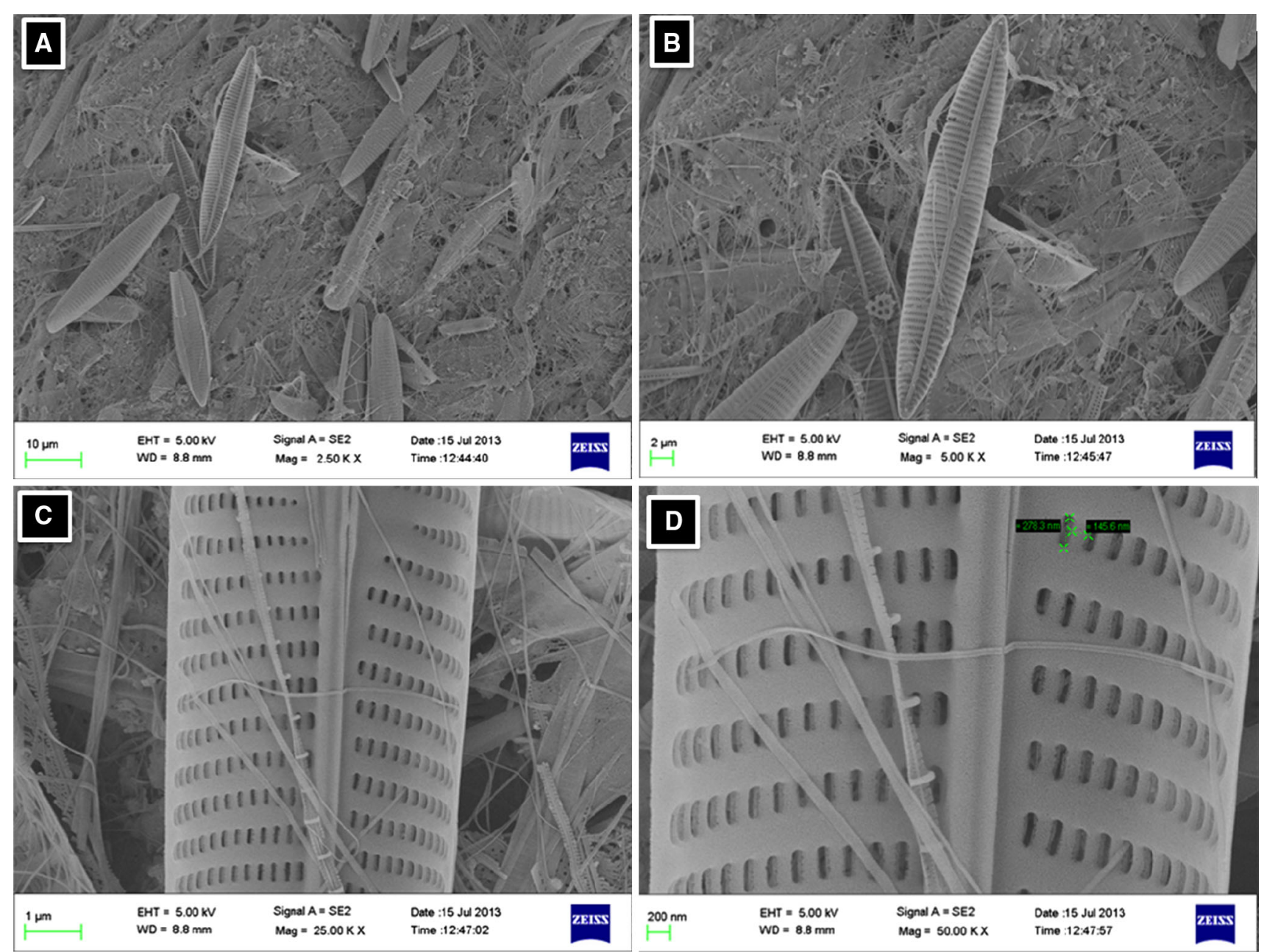

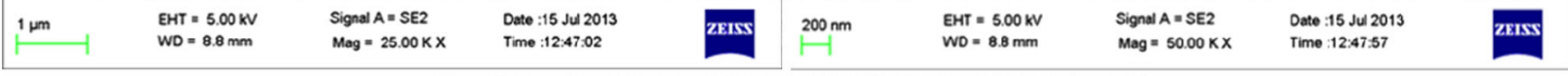
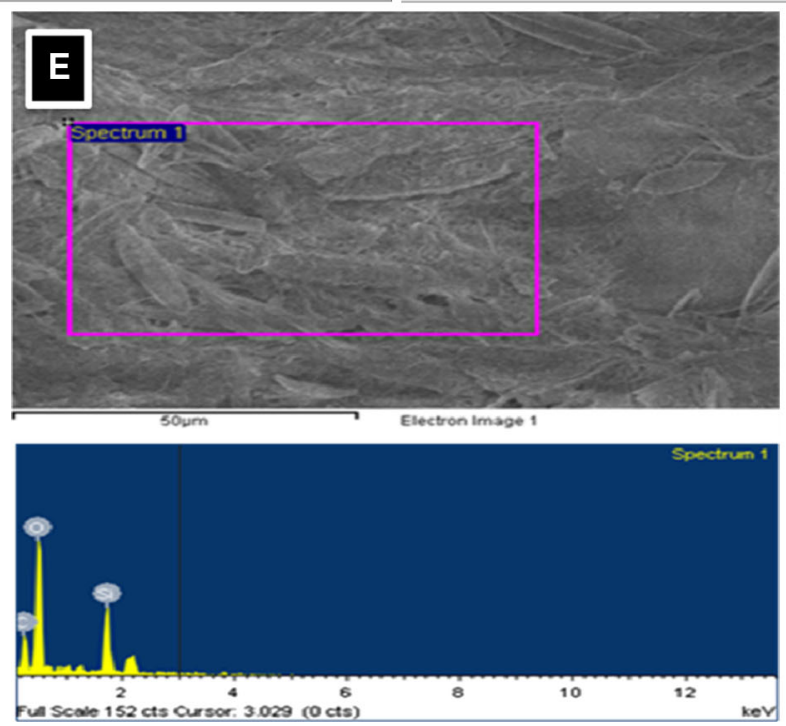

Fig. 4 Outer surface of $N$. directa a Large scale FESEM image shows organisation of holes (foramen), (b). c FESEM image of outer surface in more detail, showing striae are parallel in whole value. d Enlarged FESEM image of a foramen shows details of pore organisation $(200 \mathrm{~nm})$ and nanoporous size and between the pores size measurements are shown. e EDS graph of the pennate marine diatom frustules $(N$. directa) 
into a higher order (mesoscale) structure, while their gathering can reflect nanoscale surfaces realized in the diatom frustules [41-43]. It was fascinating that the silica frustules were twice smaller than silica particles seen in porous structure. This investigation revealed the presence of chains of interrelated silica particles (Fig. 2e), as in a three-dimensional pattern of network. The reason for the experiential alteration could be clarified by necessities for construction of a stronger porous structure using larger particles, because the each diatom has unique pore structure. Several other differences between the frustules of the two species were observed from the FESEM images. Pores in Coscinodiscus sp. were grouped together in large arrays with bigger pore. In Coscinodiscus sp. pores were organised in smaller arrays of 6-7 pores, these are regularly circulated crossways all over the surface of diatom frustules.

\subsection{Nanostructure imaging of Odontella mobiliensis frustules}

Large frustules of O. mobiliensis are presented in Fig. 3a. A series of FESEM images of the outer layer of the frustules of O. mobiliensis is presented in Fig. 3b. Outer surface of $O$. mobiliensis image shows well organised holes with same size and shape (foramen) (Fig. 3c). FESEM image of outer surface in more detail, indicate hexagonal organisation and that all the pores are circular with same size in well-arranged manner (Fig. 3d). These figures show a membrane holed by hexagonally packed pores of $328.6 \mathrm{~nm}$ diameter, spaced $252.8 \mathrm{~nm}$ (Fig. 3e). EDS graph of the centric marine diatom frustules $(O$. mobiliensis) spot analysis, confirmed that the frustules from diatoms contains mainly oxygen and silicon in the form of amorphous silica $\left(\mathrm{SiO}_{2}\right)$ (Fig. 3f; Table 3). In this study, the valves (also called microshells) of the diatom $O$. mobiliensis are regularly used for their multi-level apertures that are well organized in a flattened plane, exclusively for optical properties, large size, and flat surface, which are make them into informal of accumulate and fix [44, 45].

\subsection{Nanoporous characteristics of Navicula directa}

The girdle view of $N$. directa observed in two dimensional views was about $5 \mu \mathrm{m}$ in diameter with valve of narrow and lanceolate are subacute ends. Raphe-sternum indistinct. Striae parallel and uniformly spaced throughout the whole valve (Fig. 4a, b). FESEM image of outer surface in more detail, showing striae are parallel in whole valve (Fig. 4c). The nanometer sized pores were observed in $N$. directa in the range of $278.3 \mathrm{~nm}$, the gaps between regularly arranged pores were $145.6 \mathrm{~nm}$ was clearly observed (Fig. 4d). Fig. 4e and Table 4 graph of EDS shows the
Table 4 EDS table shows the element compositions of $N$. directa

\begin{tabular}{lcl}
\hline Element & Weight $(\%)$ & Atomic $(\%)$ \\
\hline Carbon & 16.79 & 24.65 \\
Oxygen & 48.70 & 53.68 \\
Silica & 34.51 & 21.66 \\
Totals & 100.00 & \\
\hline
\end{tabular}

pennate marine diatom frustules $(N$. directa) elemental composite. The horizontal bands present on either side of the diatoms also known as girdle bands have a higher amount of porosity Fig. 4a, b. While the girdle band production process will be inside the cell, the new girdle bands will form on the inside of the existing girdle bands and connect to the hypotheca. The shape and porosity are different from species to species of diatoms. Although the pore size stays the same. This means that the pores were more dominant on the surface as the diatoms get smaller and smaller. The pore size was same, because there were normally three layers of pores in the valves [43].

\section{Conclusions}

FESEM exploration of the three centric and one pennate cultured marine diatoms (C. concinnus, Coscinodiscus sp., $O$. mobiliensis and $N$. directa) are presented. Frustule arrangement in micro and nanoscale regime is determined in the present FESEM investigation with great detail. It is confirmed that the vital difference between these four marine diatom species are in the small pore filter plate and foramen layers. With connection to other morphological differences, the frustule size and arrangements were observed. The presented results revealed that diatom frustules formed by the accumulation of silica nanoparticulate into larger particles in the form of mesoscale nanoporous structure which might be used for taking up their nutrition, in defence mechanism and bio-mineralization. Only limited studies on morphological characteristics observation has been reported from previous SEM studies, but in the present study new structural topographies of marine diatom frustules have been obtained using FESEM imaging which are not reported elsewhere. This study showed 3D nanoporous diatom siliceous frustule that exhibited interesting multifunctional properties which should be investigated further for application in antireflection coating material because they are one of nature's most efficient light harvesting nano-structures. Therefore it can be suggested that its nano- and microporous silica shell (frustule) possess optical properties that make them attractive option for increasing the efficiency in photovoltaics research. It can also be applied for other applications like optical 
biosensors, nanocapsules for drug delivery and heavy metal adsorbing studies. A natural nanofabricated structure of diatom silica research will be a subject of future proposals for photovoltaic aspects in antireflection coating materials.

Acknowledgments We would like to thank Annamalai University authorities for support, and this work was supported by funding under fast track project file no: SERB/F/5582/2012-13 from Science and Engineering Research Board (SERB), Department of Science and Technology, New Delhi.

Open Access This article is distributed under the terms of the Creative Commons Attribution License which permits any use, distribution, and reproduction in any medium, provided the original author(s) and the source are credited.

\section{References}

1. J. Schilling, J. White, A. Scherer, G. Stupian, R. Hillebrand, U. Gösele, Appl. Phys. Lett. 86, 1 (2005)

2. G. Zhang, T. Zhang, X. Lu, W. Wang, J. Qu, X. Li, J. Phys. Chem. 111, 34 (2007)

3. D. Losic, J.R. Pillar, T. Dilger, G.J. Mitchell, H.N. Voelcker, J. Por. Mater. 14, 61 (2007)

4. M. Sumper, Science 295, 5564 (2002)

5. D. Zhang, W. Yu, C. Jun, P. Junfeng, J. Xinggang, J. Yonggang, Chin. Sci. Bull. 57, 30 (2012)

6. L. De Stefano, I. Rendina, M. Stefano, A. Bismuto, P. Maddalena, Appl. Phys. Lett. 87, 233902 (2005)

7. D. Mandal, M.E. Bolander, D. Mukhopadhyay, G. Sarkar, P. Mukherjee, Appl. Microbiol. Biotechnol. 69, 485 (2006)

8. D. Losic, J.G. Mitchell, N.H. Voelcker, Chem. Commun. 4905, 4907 (2005)

9. R.W. Drum, R. Gordon, Trends Biotechnol. 21, 325 (2003)

10. C.E. Hamm, R. Merkel, O. Springer, P. Jurkojc, C. Maler, K. Prechtel, V. Smatacek, Nature 421, 841 (2003)

11. T. Fuhrmann, S. Landwehr, M. El Rharbi-Kucki, M. Sumper, Appl. Phys. B. Lasers Opt. 78, 257 (2004)

12. R. Gordon, D. Losic, M.A. Tiffany, S.S. Nagy, F.A.S. Sterrenburg, Trends Biotechnol. 27, 116 (2009)

13. Y. Yu, J. Addai-Mensah, D. Losic, Sci. Technol. Adv. Mater. 13, 015008 (2012)

14. M. De Stefano, W.H.C.F. Kooistra, D. Marino, J. Phycol. 39, 735 (2003)

15. E. Kiefer, L. Sigg, P. Schosseler, Environ. Sci. Technol. 31, 759 (1997)

16. S.A. Craford, M.J. Higgins, P. Mulvaney, R. Wetherbee, J. Phycol. 37, 543 (2001)

17. M.J. Higgins, J.E. Sader, P. Mulvaney, R. Wetherbee, J. Phycol. 39, 722 (2003)
18. A. Linder, J. Colchero, H.J. Apell, O. Marti, J. Mlynek, Ultramicroscopy 42, 329 (1992)

19. I.C. Gebeshuber, J.H. Kindt, J.B. Thompson, Y. Del Amo, H. Stachelberger, M.A. Brzezinski, G.D. Stucky, D.E. Morse, P.K. Hansma, J. Microsc. 212, 292 (2003)

20. R. Lal, S.A. John, Am. J. Physiol. 266, C1 (1994)

21. G. Masse, M. Poulin, S.T. Belt, J.M. Robert, A. Barreaus, Y. Rince, S.J. Rowland, J. Microsc. 204, 87 (2001)

22. N. Almqvist, Y. Delamo, B.L. Smith, N.H. Thomson, A. Bartholdson, R. Lal, M. Brzezinski, P.K. Hansma, J. Microsc. 202, 518 (2003)

23. F. Round, R. Craford, D. Mann, The Diatoms (Cambridge University Press, Cambridge, 1999)

24. R. Wetherbee, S. Crawford, P. Mulvaney, in Biomineralization, ed. by E. Baeuerlein (Wiley-VCH, Weinheim, 2004), 11 p

25. D. Losic, J.G. Mitchell, N.H. Voelcker, Adv. Mater. 21, 2947 (2009)

26. K.A. Steidinger, J. Williams, Mem. Hourglass. Cruises. 2, 1 (1970)

27. G.W. Prescott, W.H.C. Brown Company Publishers, Ames, IA, USA $1954,348 \mathrm{pp}$

28. R.R.L. Guillard, in Culture of Marine Invertebrate Animals, ed. by W.L. Smith, M.H. Chanley (Plenum, New York, 1975), p. 29

29. R.A. Anderson, D.M. Jacobson, J.P. Sexton, Provasoli-Guillard Center for Culture of Marine Phytoplankton (West Boothbay Harbor, ME, 1991)

30. K.S.A. Butcher, J.M. Ferris, M.R. Phillips, M. Wintrebert-Fouquet, J.W. Jong Wah, N. Jovanovic, W. Vyvermann, V.A. Chepurnov, Mater. Sci. Eng. 25, 658 (2005)

31. M.S. Hale, J.G. Mitchell, Aquat. Microb. Ecol. 24, 287 (2001)

32. M.S. Hale, J.G. Mitchell, Nano Lett. 1, 617 (2001)

33. M.S. Hale, J.G. Mitchell, Nano Lett. 2, 657 (2002)

34. C.E. Hamm, R. Merkel, O. Springer, P. Jurkojc, C. Maler, K. Prechtel, V. Smatacek, Nature 421, 841 (2003)

35. G.R. Hasle, E.E. Syvertsen, in Identifying Marine Phytoplankton, ed. by C.R. Tomas (Academic Press, San Diego, 1996), pp. 5-385

36. F. Noll, M. Sumper, N. Hampp, Nano Lett. 2, 91 (2002)

37. T. Gutu, D. Gale, C. Jeffryes, W. Wang, C. Chang, G. Rorrer, J. Jiaol, J. Nanomater. 860536, 7 (2009)

38. S.A. Craford, M.J. Higgins, P. Mulvaney, R. Wetherbee, J. Phycol. 37, 543 (2001)

39. M. Hilderbrand, Prog. Org. Coat. 47, 256 (2003)

40. R.K. Iler, The Chemistry of silica: Solubility, Polymerization, Colloid and Surface Properties and Biochemistry (Wiley, New York, 1979), p. 866

41. N. Kroger, R. Deutzmann, M. Sumper, Science 286, 1129 (1999)

42. N. Poulsen, N. Kroger, J. Biol. Chem. 279, 42993 (2004)

43. N. Kroger, N. Poulsen, Ann. Rev. Gen. 42, 83 (2008)

44. Y. Wang, J. Pan, J. Cai, A. Li, M. Chen, D. Chem. Lett 40, 1354 (2011)

45. W. Wang, T. Gutu, D.K. Gale, J. Jiao, G.L. Rorrer, J. Am. Chem. Soc. 131, 4178 (2009) 